\title{
Returning to work following cancer: a qualitative exploratory study into the experience of returning to work following cancer
}

\author{
Kennedy F., Haslam C., Munir F. \& Pryce J. (2006) \\ F. KENNEDY, Centre of Appearance Research, Faculty of Applied Sciences, University of the \\ West of England, Frenchay Campus, Bristol, C. HASLAM, Professor, Department of Human \\ Sciences, Loughborough University, Loughborough, F. MUNIR, Department of Human Sciences, \\ Loughborough University, Loughborough, \& J. PRYCE, Psychology Department, Goldsmiths \\ College, University of London, New Cross, UK
}

\begin{abstract}
The experience of returning to work following cancer is a largely unknown area of cancer research. This preliminary study aimed to explore the factors that influence decisions about return to work either during or after cancer treatment and to identify the important aspects of returning to work. Qualitative data were collected using individual interviews ( $\mathrm{n}=19)$ and two focus groups ( $n=4, n=6$ ), predominantly with breast cancer survivors. Patterns of returning to work were diverse and a variety of reasons influenced work decisions, including financial concerns and regaining normality. Participants also discussed their ability to work, health professionals' advice, side effects, support and adjustments, and attitudes towards work. Although the majority adapted well, a few encountered difficulties on their return. It is evident that more advice is required from health professionals about returning to work, along with reasonable support and adjustments from employers to ensure that cancer survivors are able to successfully reintegrate back into the workforce.
\end{abstract}

Keywords: cancer survivors, return to work, support, adjustments. 


\section{Introduction}

Every year approximately 90 ooo individuals of working age are diagnosed with cancer and these figures are expected to rise (Cancer Research UK 2001). However, improvements in early detection and treatment have resulted in an increasing number of cancer survivors (Spelten et al . 2002). This means that many cancer patients recover and resume the activities of everyday life during or following treatment, including returning to work. Thus, cancer is not only an issue for the individuals and their families; but it is also an important issue for employers and the workplace (Schultz et al . 2002). Furthermore, from 2005 most cancer patients will be protected from discrimination at work (from the point of diagnosis) due to an amendment of the Disability Discrimination Act (DDA); employers will be expected to make reasonable adjustments for individuals living with cancer (Morell \& Pryce 2005).

Some cancer patients choose to take time off work during treatment, whereas others continue part-time or fulltime employment; this may depend on the type of cancer and treatment (Short et al . 2005), the type of work (Spelten et al . 2002), financial necessity and attitudes towards work (Mock 1998). Work is important for an individual's identity and provides a social connection; it also presents a distraction and enables the person to regain a sense of normality and control (Peteet 2000). Therefore, returning to work may enhance the patient's quality of life and be seen as a symbol of recovery (Steiner et al . 2004).

Recent research confirms that cancer survivors are productive and perform well in the workplace (Bradley \& Bednarek 2002). It is estimated that $62 \%$ of cancer patients continue or return to work during or after treatment (Spelten et al . 2002), but most previous research focuses on the probability and timeliness of returning to work, rather than identifying how the cancer experience affects the individual's quality of work life (Main et al . 2005). Maunsell et al . (1999) described various work problems that some breast cancer patients encountered such as job loss, unwanted job adjustments, reduced physical capacity and changes in work relationships. Another study showed that the experience of work after cancer is influenced by changes in productivity, social support at work, side effects, economic concerns and feelings about work (Main et al . 2005).

Some research suggests that cancer survivors find it dif- ficult to return to work after cancer treatment (Spelten et al . 2002); this can be due to work-related (e.g. work demands), diseaserelated (e.g. cancer site, side effects) or person-related factors (e.g. attitudes towards work). Fatigue is the most common side effect reported by cancer patients receiving radiotherapy, chemotherapy or recovering from surgery (Mock 1998), and can affect employment by decreasing work hours, increasing absence and reducing productivity (Messias 1997, cited in Mock 1998). Spelten et al . (2003) found that fatigue levels at 6 months after the start of sick leave predicted work status at 18 months. However, treatment reactions are highly variable, some patients experiencing few side effects, whereas others become too fatigued or emotional to work (Mock 1998).

It was recently emphasized that women who reduced or stopped working after breast cancer did so voluntarily, possibly due to valuing career goals less, turning attentions to family and enjoyment of life (Maunsell et al . 2004). Other studies have also conveyed a changed attitude among cancer survivors, attaching less importance to work than prior to their diagnosis (Maunsell et al . 1999) and valuing a more balanced approach to life (Main et al . 2005). Thus, it is important when assessing work return that the context of the individual's own priorities are considered, especially as these may have been reconfirmed or altered by the cancer journey (Steiner et al . 2004). Some individuals may even experience positive life changes 3 after their cancer (Tedeschi \& Calhoun 1995) and this could shape their work decisions (Steiner et al . 2004). Morell and Pryce (2005) reported that patients who were not offered information about managing work issues associated with their cancer were four times more likely to report that their working lives had deteriorated because of their cancer. This suggests that cancer patients require more support from both employers and the medical profession in terms of work-related 
advice, information and adjustments. Little research has explicitly investigated the adaptations in the workplace or content of work that could ease the returning process for cancer survivors (Steiner et al . 2004). In essence, when patients are provided with effective support, emotional and tangible adjustments in their work environment, they are more likely to continue and manage their illness at work (Morell \& Pryce 2005). Others emphasize that communication between occupational doctors and cancer specialists could be improved (Verbeek et al . 2003), and more involvement of doctors in requesting flexible working practices (Chirikos et al . 2002).

The aim of the present study was to explore the factors that influence cancer patients' decisions to return to work and the experience of returning to work for cancer survivors.

\section{METHODS}

\section{Participants}

Twenty-nine participants contributed to this research. Recruitment occurred primarily through six cancer support groups in the Midlands. All participants had received a cancer diagnosis in the last 10 years and reported an experience regarding returning to work during or after cancer treatment. This broad criterion aimed to provide a comprehensive insight into the experiences faced by cancer survivors, including those who had successfully returned to work, those who encountered difficulties and those who decided not to return. Nineteen individuals took part in semi-structured interviews and a further 10 participated in two focus groups $(n=4, n=6)$. The choice of method was determined by the number of volunteers from each support group and their preference for group or individual interviews.

\section{Procedure and data collection}

Nineteen face-to-face interviews lasting 20-90 min were conducted to gather participants' experience of returning to work during or after cancer treatment. Interviews took place at a convenient location, usually the cancer support group's regular meeting place, the participant's home or workplace. Demographic and cancer-specific details were collected from each participant and every interview or focus group was tape-recorded. Using a semi-structured interview guide as a reference, each interview identified the individuals' reasons for returning, any problems or difficulties, advice from health professionals, support at work, and work adjustments that helped or would have helped. Two focus groups $(n=4, n=6)$ involving 10 women with breast cancer were conducted. The women in each focus group were members of the same support group so they were familiar with each other. These discussions lasted around $90 \mathrm{~min}$. Participants were asked to talk about their experience of returning to work and a facilitator guided the discussion through five topics; reasons for returning, work after cancer, advice from health professionals, support at work and work adjustments that helped or would have helped.

\section{Analysis}

All interviews and focus group data were transcribed verbatim (maintaining anonymity), reviewed, and issues of concern that surfaced from the data were noted using the methods outlined by Silverman (2000) for interview data and by Knodel (1993) for focus group data. These issues were formulated into emergent major themes using a systematic process of reviewing transcripts, and text passages were inserted under relevant themes. This was completed separately for the interviews and focus groups to establish if there were any differences between the methods; upon review it was evident that the themes were similar from both. The results are based on thematic analysis and aimed to reveal the patterns and complexity of cancer patients' experience of returning to work. 


\section{RESULTS}

Table 1 summarizes the demographic profile of the participants. Of the 29 participants, 24 had breast cancer (one with secondary bone cancer), two had non-Hodgkin's lymphoma, two had cancer of the uterus (one also with ovarian and cervical cancer) and one had cancer of the larynx. The mean age of the participants was 52.6 years, at diagnosis was 47.2 years; 27 were women and most were married (19). Average time since diagnosis was 59.8 months (range 11-118 months); most participants (26) were employed at the time of diagnosis, and two were fulltime students and one was newly redundant.

\section{Return to work and changes following cancer}

Various patterns of work return and changes were experienced following the cancer diagnosis or treatment. Of the 29 participants, most stated that they temporarily stopped working (24), seven of these had a short time off for postoperative recovery (3-9 weeks) and worked during further treatments, 17 continued on sick leave during treatments (3-18 months). However, two participants did not return to work, and the remaining three participants continued working throughout; these individuals worked part-time prior to their diagnosis and made no changes during treatment (except taking a few days off for their operation). Overall, among those who did return to work (27), 10 returned to the same job and schedule, nine decreased or changed their hours, two reduced their hours and changed their job role, three changed employer and three became self-employed.

\section{Factors influencing post-cancer work decisions}

Numerous factors influenced participants' decision about work return following or during cancer treatment; some felt this was an unconscious decision, while others felt they were ready, were under financial pressure or wanted to regain normality .

\section{Financial}

Many participants spoke about the financial pressure of being off work and almost half (13) indicated that this was the primary reason for returning. Essentially, they did not have a choice once their sick pay had expired, as this 61- year-old widowed secretary explained:

I didn't feel as though I had any choice not to return to work ... I live alone and I've got a mortgage, and at that time I'd got my youngest son still going through university and so to an extent he was still a bit dependent.

In contrast, others (5) spoke of how they felt fortunate not having to return to work immediately or worry financially because they were paid throughout their treatment. A few participants also mentioned the benefits system, and two participants found the arrangements available very helpful, especially the 'permitted work' scheme, where they were able to work part-time and claim a portion of their sick pay and incapacity benefit. However, one woman found she could not claim incapacity benefit because she had not paid enough national insurance contributions and others felt that applying for these benefits was an insensitive experience:

Fifty page forms ... having breast cancer seems to somehow not fit within these pages and if I couldn't walk, fine, but it glossed over what you're going through, the fact that you were knackered and couldn't do anything.

\section{Normality}

Around one-third of participants (10) emphasized that they used work as a distraction from their illness or treatment to regain a sense of normality. This 44-year-old woman explained:

Going back to work for me is about just being slightly more normal, because going through cancer isn't normal, and going back to work ... going in, enjoying my job, making a difference. 
5 Returning to work following cancer. Goldsmiths Research Online.

And my family seeing me going to work and seeing that I'm not at death's door yet is what I want.

Several individuals also reported that they enjoyed the social network of work; one 49-year-old secretary who returned to work while undergoing chemotherapy described that she felt emotionally better at work.

\section{Physical health}

A few participants saw their physical health as influencing their work return. One 44-year-old woman with non- Hodgkin's lymphoma retired due to ill health because she was not physically well enough to return to her job. Conversely, for others returning to work was not a conscious decision; it was just the natural thing to do once they felt well enough.

\section{Work influence}

Responsibility and feelings of loyalty to work was another prominent factor, especially in smaller workplaces that struggled to cope with the extra workload. Additionally, a couple of participants described feeling coerced into returning by their workplace:

I was sent to see the occupational health doctor because I'd had such a long time off . . . I returned to work because he showed me the letter from the manager ... there was an extremely strong unwritten, between the lines message, that if I didn't return to work they wanted me to finish.

\section{Health professionals' advice}

There was a mixture of experiences regarding health professionals' advice about work return. Some (8) described how work issues were never discussed and they were not even sure if their doctor knew whether they were working or not. One 58 -year-old nurse with breast cancer who underwent chemotherapy and radiotherapy, which reduces the individual's immune system, was never asked whether she would be exposed to infection at work. A few explained how their doctor or specialist gave them specific guidance about their work return. This 57-year-old man described how this influenced his decision:

I saw my consultant and he said 'by now you should be feeding yourself back into work', so it was really them telling me I was well enough, that the cancer was behind me.

However, many others emphasized how the doctors left them to decide for themselves. Most understood the difficulty for doctors to give personal advice because individuals react diversely, but some indicated more advice or information would have helped. This 51-yearold secretary who had access to a breast care nurse expressed the positive impact this advice and support provided:

She said it's completely down to the individual as to how you are, some people have a year off and others, like myself, carry on throughout. It depends on the individual. But they touched on a lot of the personal side ... affecting your home life and work life.

\section{Experience of work after cancer}

Within the sample, the experience of returning or continuing to work after cancer diagnosis or treatment was diverse. Productivity varied and many spoke of their employer and colleagues' expectations.

\section{Ability to work}

Some respondents reported that they were able to return to work, function effectively and perform as they had previously. In contrast, around a third revealed how it was initially difficult to cope and concentrate; they worried about their reduced capability and felt they were letting the 
company down. This 57-year-old man with non- Hodgkin's lymphoma was concerned about the stress of performing:

It would worry me that I'd be letting the company down and not meeting deadlines because I wouldn't want to inflict stress on myself, I would be sitting there watching, doing some work but not doing it at the pace they would want.

A 38-year-old woman who originally returned to work part-time went back onto sick leave after 6 weeks because the pressure of her job became overwhelming: After about two weeks I became very tearful, I wasn't doing my job properly and I was forgetting things . . . I realized that I, well I couldn't cope really, I was just really struggling.

Many participants acknowledged that the type of work influenced their working lives; generally, those in already stressful jobs found it more difficult when returning. This 58 -year-old nurse compared herself with a friend who returned easily:

There's a friend down the road, she's a receptionist and ... it actually did her good going into work, but I'm just faced with everybody's problems ... . a barrage of other people's health problems and I didn't feel as though I could cope.

\section{Expectations}

Almost a third referred to the expectation they felt from their employer or colleagues once they returned; this was especially difficult for those who felt they could not perform initially. This 44year-old woman who decided not to return to work explained:

They'd soon forget how tired you get and then you'd just be part of the fixture and fittings, they'd forget all about that and then you'd be exhausted, but they'd be expecting you to perform.

Others spoke of their own expectation and the realization that they would need time to recover; some also suggested that if they looked well, this might mislead employers into thinking they had completely recovered. I think you finish your treatment and, 'oh good, I'm all right now, it's behind me' but it takes a long time to get actually back to your normal self ... And that's what employers can think ... it's behind you and you're looking alright.

Another issue was the need for ongoing appointments with specialists. Some had to make the time up if the appointment was during work hours, whereas others were given paid time off; but overall this caused added pressure and worry.

I felt awkward because you've constantly got appointments ... obviously you can't get all of those in the evening. And having had time off work I felt very guilty having to say I'd got these appointments.

One 56-year-old civil servant also described how her job was transferred without her agreement while she was on sick leave and this made returning a challenge because she had to work with new colleagues and was not given any opportunity to review the situation.

\section{Effects of the cancer and treatment}

Numerous physical side effects were referred to, and some were dependent on the type of cancer or treatment, including lymphoedema and arm swelling, bowel and urinary problems, speech difficulties, nausea, depression, soreness and reduced concentration. However, tiredness and fatigue were the most frequent side effect that was disruptive and difficult to manage at work, and many spoke of how this lasted for months or even years after the treatment. 
Occasionally days where the tiredness just sweeps over you and I'm almost past those but for the first five years the fatigue, it is the only word that you can describe is extreme ... fatigue, where you just don't have the energy to get up.

Several participants mentioned increased susceptibility to infections; this often meant they needed more time off for minor illnesses. In contrast, around a quarter of participants (7) reported that they had no significant side effects and they felt fortunate in this respect. The occurrence of hair loss and the need to wear a wig was also considered a difficulty in the workplace; a number of women reported feeling uncomfortable in their wig and also selfconscious the first time they removed it, describing the hair loss as 'one of the worst things that happened'. Some of the breast cancer women expressed difficulties and worries about their new prosthesis and clothing at work.

If I had to lean down to do anything on the bottom, lower shelf or even for bags to pack them, I was like this [covered her chest] all the time, holding it together ... every minute of my working day you're thinking of it.

Although we didn't mix with the lads, it was mainly a male, young male office. I was very conscious of the soreness, because I couldn't wear a bra and so I used to layer clothes on so it wasn't sort of obvious. A number of participants also mentioned the emotional aspect of being diagnosed and treated, and one woman found that returning to work heightened the reality of what she had experienced.

\section{Support and adjustments at work}

The support received from work varied but included support at diagnosis, during sick leave and on their return, and ranged from practical help, adjustments and emotional support.

\section{Support}

All the participants reported that they told their employer about the cancer; usually at the time of diagnosis when it was evident, they would need time off for treatment. This was generally met with shock and sympathy. The majority (20) spoke of the great support they received from employers and colleagues while they were off work, when they returned and how this helped ease them back into work.

Everybody supported me, and in a way for the first few months carried me ... where I didn't get work finished they would finish it off for me.

However, a minority of participants described negative reactions and support they encountered at work. One woman with cancer of the uterus reported how the personnel department never contacted her following her return to see how she was coping or to offer any support.

A couple of participants faced mixed support: a 38-yearold woman described how her boss was initially supportive, but when she returned 4 days a week on her day off she would get phonecalls and faxes from the office, which made her feel very upset and harassed:

I thought hold on a second ... I'm supposed to be having a day off, I'm not getting paid for it and the whole point was to chill, forget about work and here you are putting pressure on me ... I couldn't quite work out in my mind what was going on really in that he'd been supportive, but I didn't see that as being supportive.

Others spoke of the lack of understanding from their employer and colleagues over the support they needed, although they recognized that this was due to lack of awareness and information. 


\section{Adjustments}

Adjustments that were offered were based around flexibility, gradual assimilation and changes in work tasks; some were offered these automatically, but others had to request them. The size of the organization was highlighted as influencing the accommodations available; larger organizations were seen to offer more services and support. Many participants mentioned how the flexibility of their jobs helped them acclimatize back into work; this was especially apparent in those who became selfemployed, including this 54-year-old man who illustrated how his freelance schedule was favourable:

It enabled me to manage my health at that time. So if I woke up in the morning and didn't feel well, as long as I didn't have a meeting, then I wasn't doing the work that day ... I would give myself flexibility in the deadlines.

Other individuals whose jobs were flexible found this to be very beneficial, especially this 45 -yearold development manager who worked throughout her chemotherapy and radiotherapy:

The nature of my job, I work from home ... I might just go to bed in the afternoon, and then get up and carry on. So although I carried on working full-time there was a lot of flexibility in my days.

Most participants indicated how their employer was able to make accommodations to their work, which ranged from changing work hours, altering tasks or initially reducing their workload.

She [colleague] took more responsibility, I did the sort of more menial tasks ... she took the more detailed work and I did what I could. So the work changed and then after I got better from the chemo then we sort of switched back.

However, a few participants felt there were more adjustments their employers could have offered to help them reintegrate. An important paradoxical feeling about returning to work was raised in one of the focus groups; individuals agreed that they wanted to be treated normally at work, did not want to be labelled as a cancer patient, but they also felt they needed some support or allowances. This highlights how employers may find it difficult to strike the balance between giving support and allowing the employee to return to normality.

\section{Attitudes about work}

Many participants spoke about how their cancer journey has changed their perception of work, made them question its relevance and prompted them to re-evaluate their priorities. Some conveyed they were less ambitious about work and others expressed how they wanted to live life to the full.

I'm not nearly as ambitious as I was ... I would like enough money to be able to live comfortably ... I'm not aspiring to have loads of money, that's not ... what its about, it's about enjoying life and getting a balance between work and home.

Some described how the experience has changed how they behave at work because they do not allow themselves to get stressed anymore, and many highlighted the possible link between stress and cancer.

I don't want to see myself getting involved in that again ... although doctors say '. . . stress can be a factor but stress doesn't cause cancer' ... I was so stressed that my mind is telling me that stress causes, is one of the major contributory factors to the body breaking down and cancer coming out. 
9 Returning to work following cancer. Goldsmiths Research Online.

\section{DISCUSSION}

This study provides an in-depth exploration into the experience of returning to work following cancer. The results are consistent with the small amount of previous research (Spelten et al . 2002; Main et al . 2005). The majority described that they temporarily left work to recover from the operation or during treatments. Participants reported many considerations that influenced their post-cancer work decisions; however, like Main et al . (2005) most indicated that financial concerns were a significant issue. This also concurs with the CancerBACUP report that almost two-thirds of its respondents had experienced financial problems during their treatment (Morell \& Pryce 2005). Participants' desire to return to normality and distract themselves from the cancer was another major reason to return; after the focus of their life had been on fighting the disease, many wanted to move on and regain control of their lives (Peteet 2000).

Most respondents indicated that they received little advice from health professionals about work issues. This is consistent with two former studies that concluded that most cancer patients do not discuss return to work issues with their doctors (Maunsell et al . 1999; Main et al . 2005). Some participants emphasized how difficult it was for doctors to give individual advice, due to the diverse nature of reactions to the treatments (Mock 1998). Nevertheless, this area needs to be addressed and it is evident that an improvement in communication about readiness to return to work and work issues (e.g. side-effect management) would be advantageous.

Although many of the cancer survivors reported adjusting well, a few experienced difficulties that made returning to work a challenge. Some emphasized distress at not being able to perform as efficiently as before, especially if they felt their employers or colleagues were expecting them to be back to normal. Various side effects were reported; extreme fatigue was the most frequent symptom that was disruptive and difficult to manage at work (Spelten et al . 2003). These feelings continued for months or even years after the treatment; therefore, the long-term implications for cancer survivors should be highlighted to employers. However, it is equally important not to overemphasize the possible problems because the majority of cancer patients return to perform well in the workplace (Bradley \& Bednarek 2002). Most participants received valuable support from their employer and colleagues throughout their cancer experience, on both practical and emotional levels, and this clearly enhanced the return to work process for these

individuals. Nearly all employers made adequate accommodations and what was generally helpful was simply allowing the employee to be flexible and gradually assimilate back into work (Morell \& Pryce 2005). Unfortunately, a minority experienced problems or unsupportive reactions from their workplace and this undoubtedly affected the individual's feelings about work (Spelten et al. 2002). There is wide diversity among organizations in their capacity to offer flexible arrangements; thus, in some jobs it may be a challenge to provide this. Interestingly, it was emphasized by several participants that employers may be unaware of the services and support that could help, which indicates the need for further research and recommendations to be given to employers (Morell \& Pryce 2005). This concurs with the suggestion that some employers' failure to make adequate provisions for cancer patients is due to a culture of ignorance within organizations about the needs of employees diagnosed with cancer (Morell \& Pryce 2005).

The experiences collected in this study were primarily from individuals with breast cancer, due to the high proportion of breast cancer support groups that are established and agreed to partake. Consequently, the conclusions gathered do not necessarily reflect those of cancer survivors more generally. In addition, the time since diagnosis in the sample ranged from 11 to 118 months, average 59.8 months, and this is much longer than the previous qualitative study (31.6 months; Main et al . 2005). Therefore, some individuals' recollections would be more dependent on their memory; and it is important to acknowledge that practices may have changed over the years. Furthermore, the relatively small sample prevented a more in-depth examination and comparison of individuals with different diagnoses, job types and experiences. Further qualitative research comparing these factors, supported by quantitative data would strengthen the data interpretability. 
10 Returning to work following cancer. Goldsmiths Research Online.

However, this study provides some important insights into the experience of returning to work for cancer patients. Essentially, to complete the cancer journey and enable cancer survivors to reintegrate into a healthy and satisfying working life, there is a need for support, advice and accommodations from various directions. Evidently, improvements could be made to the workrelated advice and information given to patients by health professionals. Employers must also ensure they provide support and reasonable accommodations; this will hopefully improve with the amendment to the DDA. Further research also needs to survey organizations to identify their policies towards and support of returning cancer patients. Essentially, cancer is not merely a medical or personal issue; it can be influenced by the wider social structure surrounding the individual. It is hoped that these findings will help highlight the dynamics of work return for cancer survivors and inform future service improvements, in terms of both occupational health advice during treatment and enhancing employers' awareness of their responsibility in supporting employees' returning to work following cancer.

\section{REFERENCES}

Bradley C.J. \& Bednarek H.L. (2002) Employment patterns of long-term cancer survivors. PsychoOncology $11,188-198$.

Cancer Research UK (2001) Statistics on the Incidence of Cancer by Age-Group . Available at: http://info.cancerresearchuk.org/ cancerstats/incidence/age/?a =5441 (accessed 25 February 2005).

Chirikos T.N., Russell-Jacobs A. \& Cantor A.B. (2002) Indirect economic effects of long-term breast cancer survival. Cancer Practice 10, 248-255.

Knodel J. (1993) The design and analysis of focus groups. In: Successful Focus Groups: Advancing the State of the Art (ed. Morgan D.L.), pp. 35-50. Sage Publications, Thousand Oaks, CA, USA.

Main D.S., Nowels C.T., Cavender T.A., Etschmaier M. \& Steiner F. (2005) A qualitative study of work and work return in cancer survivors. Psycho-Oncology 14, 992-1004.

Maunsell E., Brisson C., Dubois L., Lauzier S. \& Fraser A. (1999) Work problems after breast cancer: an exploratory qualitative study. Psycho-Oncology 8, 467-473.

Maunsell E., Drolet M., Brisson J., Brisson C., Mâsse B. \& Deschênes L. (2004) Work situation after breast cancer: results from a population-based study. Journal of the National Cancer Institute 96, 1813-1822.

Mock V. (1998) Breast cancer and fatigue: issues for the workplace. AAOHN Journal 46, 425-431.

Morell J. \& Pryce J. (2005) Work and Cancer: How Cancer Affects Working Lives. CancerBACUP: Ashford Colour Press. Available at:

http://www.cancerbacup.org.uk/News/Press/ Pressreleasesstatements/2005/45691514 (accessed 25 February 2005).

Peteet J.R. (2000) Cancer and the meaning of work. General Hospital Psychiatry 22, 200-205.

Schultz P.N., Beck M.L., Stava C. \& Sellin R.V. (2002) Cancer survivors: work related issues. AAOHN Journal 50, 220- 226.

Short P.F., Vasey J.J. \& Tunceli K. (2005) Employment pathways in a large cohort of adult cancer survivors. Cancer 103, 1292- 1301.

Silverman D. (2000) Doing Qualitative Research: A Practical Handbook. Sage Publications, London, UK. Spelten E.R., Sprangers M.A. \& Verbeek J.H. (2002) Factors reported to influence the return to work of cancer survivors: a literature review. Psycho-Oncology 11, 124-131.

Spelten E.R., Verbeek J.H., Uitterhoeve A.L., Ansink A.C., van der Lelie J., de Reijke T.M., Kammeijer M., de Haes J.C. \& Sprangers M.A. (2003) Cancer, fatigue and the return of patients to work: a prospective cohort study. European Journal of Cancer 39, 1562-1567. 
11 Returning to work following cancer. Goldsmiths Research Online.

Steiner J.F., Cavender T.A., Main D.S. \& Bradley C.J. (2004) Assessing the impact of cancer on work outcomes: what are the research needs? Cancer 101, 1703-1711.

Tedeschi R.G. \& Calhoun L.G. (1995) Trauma and Transformations: Growing in the Aftermath of Suffering. Sage Publications, Thousand Oaks, CA, USA.

Verbeek J., Spelten E., Kammeijer M. \& Sprangers M. (2003) Return to work of cancer survivors: a prospective cohort study into the quality of rehabilitation by occupational physicians. Occupational Environmental Medicine 60, 352-357. 
In press: European Journal of Cancer Care. Accepted 3 August 2006

\begin{tabular}{|c|c|c|c|c|c|c|c|c|}
\hline $\mathrm{Pp}^{*}$ & $\begin{array}{l}\text { Age } \\
\text { (years) }\end{array}$ & Gender & Marital status & Cancer site & $\begin{array}{l}\text { Time } \\
\text { since diagnosis }\end{array}$ & Treatment & Employment & Work status $\ddagger$ \\
\hline 1 & 58 & Female & Married & Breast & 89 & $L \& R$ & Nurse & 3 weeks \\
\hline 2 & 54 & Male & Married & Larynx & 118 & Op \& R & Teacher & 12 months \\
\hline 3 & 44 & Female & Widowed & $\begin{array}{l}\text { Non-Hodgkin's } \\
\text { lymphoma }\end{array}$ & 49 & Op \& C & Operational planner & Retired (ill-health) \\
\hline 4 & 58 & Female & Living with partner & Breast & 47 & $\mathrm{~L}, \mathrm{C} \& \mathrm{R}$ & Nurse & 11 months \\
\hline 5 & 61 & Female & Widowed & Uterus & 111 & Op \& R & Secretary & 6 months \\
\hline 6 & 51 & Female & Married & Breast & 59 & $M, C, R \& T$ & Secretary & 9 weeks \\
\hline 7 & 40 & Female & Single & Breast & 14 & $L, C, R \& T$ & $\begin{array}{l}\text { Student/self- } \\
\text { employed }\end{array}$ & 3 weeks \\
\hline 8 & 45 & Female & Divorced & Breast & 61 & $L, C, R \& T$ & $\begin{array}{l}\text { Development } \\
\text { manager }\end{array}$ & 5 weeks \\
\hline 9 & 38 & Female & Living with partner & Breast & 11 & $C, M \& R$ & Loss adjuster & $\begin{array}{l}11 \text { months, now sick } \\
\text { leave again }\end{array}$ \\
\hline 10 & 66 & Female & Widowed & Breast & 66 & $M, C \& R$ & Teacher & Part-time \\
\hline 11 & 50 & Female & Single & Breast & 66 & $\mathrm{M}$ & Care assistant & 6 months \\
\hline 12 & 64 & Female & Married & Breast & 84 & $M, R, C \& T$ & Nurse & 3 months \\
\hline 13 & 58 & Female & Married & Breast & 97 & $M, C \& R$ & Retail & Quit/12 months \\
\hline 14 & 56 & Female & Married & Breast & 78 & $L \& R$ & Retail & 18 months \\
\hline 15 & 44 & Female & Married & Breast (bone) & 11 & $\mathrm{M}, \mathrm{C}$, bone drip \& $\mathrm{T}$ & $\begin{array}{l}\text { Learning support } \\
\text { assistant }\end{array}$ & 15 months \\
\hline 16 & 60 & Female & Married & Breast & 108 & $M, R, C \& T$ & Accounts cler $\mathrm{k}$ & Part-time \\
\hline 17 & 57 & Male & Married & $\begin{array}{l}\text { Non-Hodgkin's } \\
\text { lymphoma }\end{array}$ & 96 & Op, C \& R & Chemical industry & 9 months \\
\hline 18 & 49 & Female & Married & Breast & 24 & $\mathrm{M}, \mathrm{C} \& \mathrm{R}$ & Secretary & 5 weeks \\
\hline 19 & 52 & Female & Married & $\begin{array}{l}\text { Uterus, ovarian \& } \\
\text { cervical }\end{array}$ & 29 & $\begin{array}{l}\text { Op, C, R \& intense } \\
\mathrm{R}\end{array}$ & Teacher & 7 months \\
\hline 20 & 42 & Female & Married & Breast & 85 & $\mathrm{M} \& \mathrm{OC}$ & Student & 6 months \\
\hline 21 & 61 & Female & Married & Breast & 109 & $M, C \& R$ & Pharmacy assistant & 5 weeks \\
\hline 22 & 47 & Female & Married & Breast & 51 & $M, C \& R$ & $\begin{array}{l}\text { Customer care } \\
\text { assistant }\end{array}$ & 10 months \\
\hline 23 & 36 & Female & Single & Breast & 37 & $M, C \& R$ & Customer service & 4 weeks \\
\hline 24 & 51 & Female & Living with partner & Breast & 26 & $M, C, R \& T$ & Care assistant & 9 months \\
\hline 25 & 65 & Female & Married & Breast & 60 & $\mathrm{M}$ & Teacher & 6 months \\
\hline 26 & $58 \mathrm{~d}$ & Female & Married & Breast & 35 & $\mathrm{~L}, \mathrm{R} \& \mathrm{~T}$ & Revenue assistant & Retired \\
\hline 27 & 49 & Female & Married & Breast & 19 & $\mathrm{M}, \mathrm{R}, \mathrm{HI} \& \mathrm{~T}$ & Newly redundant & 3 months \\
\hline 28 & 56 & Female & Married & Breast & 80 & $\mathrm{~L}, \mathrm{C} \& \mathrm{R}$ & Civil servant & 11 months \\
\hline 29 & 55 & Female & Married & Breast & 63 & $M \& O C$ & Retail & Part-time \\
\hline
\end{tabular}

${ }^{*}$ Participant number, individual interviews $=1-19$, focus group $1=20-23$, focus group $2=24-29$. $†$ Time since diagnosis (months), overall average $=59.8$, interviewees $=61.6$, focus groups $=56.5$. $¥$ Work status = amount of time off during or after treatment. M, mastectomy; L, lumpectomy; C, chemotherapy; R, radiotherapy; OC, Oral chemotherapy; Op, operation;

$\mathrm{T}$, tamoxifen; HI, hormonal injection. 